\title{
Transcriptional Regulation of Cortical Interneuron Development
}

\author{
Simon J. B. Butt, ${ }^{1}$ Inma Cobos, ${ }^{2}$ Jeffrey Golden, ${ }^{3}$ Nicoletta Kessaris, ${ }^{4}$ Vassilis Pachnis, ${ }^{5}$ and Stewart Anderson ${ }^{6}$ \\ ${ }^{1}$ Skirball Institute, New York University, New York, New York 10016, ${ }^{2}$ Department of Cell Biology, University of Barcelona, 08007 Barcelona, Spain, \\ ${ }^{3}$ Department of Pathology, Children's Hospital of Philadelphia, Philadelphia, Pennsylvania 19104, ${ }^{4}$ Wolfson Institute for Biomedical Research, University \\ College London, London WC1E 6BT, United Kingdom, ${ }^{5}$ Division of Molecular Neurobiology, National Institute for Medical Research, London NW7 1AA, \\ United Kingdom, and ' $D$ Department of Psychiatry, Weill Cornell Medical College, New York, New York 10065
}

Key words: fate determination; Dlx; Nkx; Lhx; Arx; MGE; CGE; interneuron

GABAergic interneurons modulate both the development and function of the cerebral cortex through the actions of a variety of subtypes. Despite the relevance to cortical function and dysfunction, including seizure disorders and neuropsychiatric illnesses, relatively little is known about the transcriptional regulation of interneuron development. This situation has occurred partly because of the difficulty of characterizing interneuron subtypes. An additional problem is the inherent challenge of studying fate determination of cells that even in rodents do not fully differentiate until weeks after their birth in utero. Here we seek to highlight recent findings on transcriptional regulation of interneuron development and thereby to inform the next generation of studies in this burgeoning field.

\section{Overview of GABAergic interneuron function}

GABAergic interneurons represent $\sim 20 \%$ of the neurons in the mouse cerebral cortex (Tamamaki et al., 2003). GABA acts predominantly via postsynaptic chloride-permeable ionotropic $\mathrm{GABA}_{\mathrm{A}}$ receptors to shunt or hyperpolarize target cells. As such, GABAergic interneurons are crucial to regulating the firing activity and entraining the principal neuronal component in the cerebral cortex: the glutamatergic projection neurons or pyramidal cells (Cobb et al., 1995; Thomson et al., 1996; Tamas et al., 2000).

At a basic level, the function of any given inhibitory GABAergic interneuron within a cortical network can be regarded as the sum of (1) the afferent inputs onto the cell, (2) the synaptic targets of the cell, and (3) the intrinsic properties of the neuron. However, our understanding of how these cells respond to ongoing activity to entrain target cells has been limited by the sheer diversity of interneuron subtypes encountered in the mature cortex (for review, see Somogyi et al., 1998; Markram et al., 2004). One approach to better discriminate different cell types and provide a template for the further investigation of interneuron func-

Received Aug. 2, 2007; revised Sept. 14, 2007; accepted Sept. 16, 2007.

This work was supported by Human Frontiers Science Programme (S.J.B.B.), grants from the National Institutes of Health (NIH) to the Gordon Fishell laboratory at New York University, a Medical Research Council New Investigator Award (N.K.), National Institute of Neurological Disorders and Stroke Grant NS46616 (J.G.), and NIH Grants MH066912, MH070031, and NSO48120 (S.A.).

Correspondence should be addressed to Dr. Stewart Anderson, Department of Psychiatry, Weill Cornell Medical College, Box 244, 1300 York Avenue, New York, NY 10065. E-mail: saa2007@med.cornell.edu.

DOI:10.1523/JNEUROSCI.3525-07.2007

Copyright $\odot 2007$ Society for Neuroscience $\quad$ 0270-6474/07/2711847-04\$15.00/0 tion has been to link early developmental events with more mature postnatal physiological properties. The premise behind this line of investigation is that the divergence in mature properties reflects the end result of a complex developmental cascade. The discovery of key steps in this process will allow better discrimination of subtypes, identify potential disease genes, and promote the development of genetic tools for studying interneuron function on the neuronal, network, and behavioral levels.

\section{Distinct spatial and temporal origins of interneuron subgroups}

Studies from many laboratories have shown that cortical interneurons in rodents are born in subcortical regions and migrate tangentially over long distances to populate the cortex and the hippocampus (for recent review, see Marin and Rubenstein, 2003; Metin et al., 2006; Wonders and Anderson, 2006). Although similar migrations appear to occur in gyrencephalic mammals, including ferrets and humans (Anderson et al., 2002; Letinic et al., 2002; Poluch et al., 2007), primates may have an additional interneuron source within the cortical neuroepithelium (Letinic et al., 2002). As such, it is tempting to speculate that vertically oriented bipolar or bitufted calretinin-expressing interneurons, which are far more numerous in primate cortex than in rodents (Gabbott and Bacon, 1996; Gabbott et al., 1997; Tamamaki et al., 2003), have evolved a cortical origin in primates. If so, it is interesting to note that a cortical origin of these cells does not appear to exist in ferrets (Anderson et al., 2002).

Subcortical origins of cortical interneurons have been traced to neuroepithelial cells of the medial (MGE), lateral (LGE), and caudal (CGE) ganglionic eminences (Fig. 1A). Genetic studies using tools that allow indelible labeling of the subcortical telencephalon and its cellular progeny demonstrate that molecularly distinct regions of the neuroepithelium generate distinct cortical interneuron subgroups (Fogarty et al., 2007). The MGE appears to give rise primarily to parvalbumin (PV)- or somatostatin (SOM)-expressing subgroups, whereas the CGE gives rise primarily to vertically oriented, bipolar or bitufted cells that express calretinin (CR). Indeed, in vivo transplantation studies of fluorescently tagged MGE or CGE precursors followed by electrophysiological analysis of interneurons at postnatal stages demonstrated that interneuron subclasses with different electrophysiological, morphological, and immunohistochemical profiles are generated from different subcortical regions (Butt et al., 

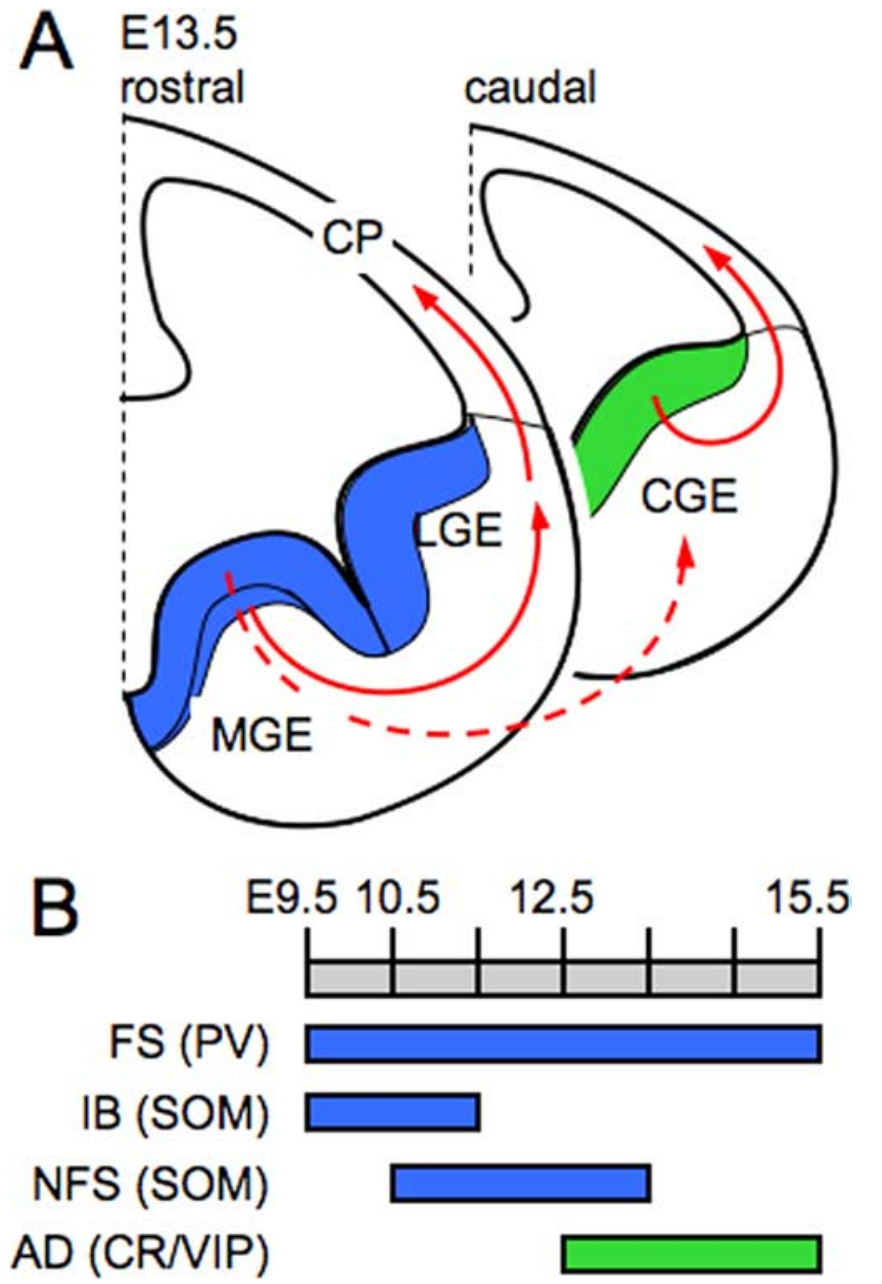

Figure 1. Subcortical origins of cortical interneurons in the mouse telencephalon. $\boldsymbol{A}$, Diagram showing rostral and caudal coronal sections through an embryonic [embryonic day 13.5 (E13.5)] mouse telencephalon. The large majority of cortical interneurons originate from the proliferative zone (PZ) (the ventricular and subventricular zones) of two subcortical structures, the MGE (blue PZ) and (GE (green PZ), before migrating tangentially (filled red arrows) into the developing cortical plate (CP). Transplantation experiments suggest that interneurons from the MGE also migrate caudally (dashed red arrow) via the (GE before undergoing tangential migration. $\boldsymbol{B}$, Evidence from both transplantation and genetic fate-mapping experiments has revealed distinct spatial and temporal origins for distinct physiological subtypes of interneuron as assayed by their intrinsic properties. The bulk of interneuron neurogenesis occurs from E9.5 until E15.5 (gray scale bar). Fast spiking interneurons, most of which express PV, burst spiking interneurons (IB), most of which express SOM, and SOM-positive nonfast spiking interneurons (NFS) originate from the MGE with different temporal profiles (blue histogram bars). Adapting (AD) interneurons, which primarily express (R and/or vasoactive intestinal peptide (VIP), originate at later time points from the CGE (green bar).

2005). These results indicate that the interneuron origins are predictive of multiple aspects of their mature phenotype. It also suggests that underlying differences in gene expression between different regions are responsible for the differential potential of progenitors from these regions to achieve a given interneuron phenotype.

Beyond the evidence for distinct spatial origins of interneuron subgroups or subtypes, there are also distinct temporal origins between interneuron subgroups. Within a given layer, the mainly CGE-derived bipolar vasoactive intestinal peptide- and CRexpressing interneurons are generally later born than those that express SOM (Cavanagh and Parnavelas, 1988, 1989). Interestingly, the CGE-derived interneurons also lack the inside-out relationship between birthdate and laminar location shown by the MGE-derived subgroups and cortical projection neurons (Cavanagh and Parnavelas, 1989; Miyoshi et al., 2007; Rymar and Sadikot, 2007). Using careful titration of inducible fate mapping with an Olig2-Cre (oligodendrocyte transcription factor 2-enterobacteria phage $\mathrm{P} 1$, cyclization recombinase) transgenic mouse, this analysis has recently been extended to the physiological level of subclassification (Fig. $1 B$ ), in which distinct temporal origins of physiologically defined subclasses of interneurons have been identified (Miyoshi et al., 2007). These experiments suggest that competence to achieve a given interneuron phenotype is specified early in development. As knowledge regarding the genetic code underlying specification develops, so does the possibility that researchers in other fields beyond developmental genetics will be able to use these resources to more precisely target and manipulate interneuron populations.

\section{Fate determination of cortical interneuron subgroups}

Although a genetic code for fate determination is currently far from being elucidated for any cortical interneuron, important inroads into the regulation of interneuron fate are beginning to be uncovered. Expression of the transcriptional factor Nkx2.1 (NK2 transcription factor-related 2.1) in the MGE is required for the specification of the MGE-derived interneuron subgroups that express PV or SOM (Sussel et al., 1999; Xu et al., 2004). Upstream of Nkx2.1, the morphogen Sonic hedgehog (Shh) appears to play a critical role in both the establishment of $\mathrm{Nkx} 2.1$ expression in the MGE (Chiang et al., 1996; Fuccillo et al., 2004) and in the maintenance of this expression during the age range of neurogenesis (Xu et al., 2005). Preliminary evidence suggests that there may be a link between levels of Shh signaling in MGE progenitors and the subgroups of interneurons that they generate (C. P. Wonders and S. Anderson, unpublished observations). Downstream of $\mathrm{Nkx} 2.1$, the interneuron-specifying function of $\mathrm{Nkx} 2.1$ may depend on its direct activation of the lim-homeodomain transcription factor Lhx6 (T. Du and S. Anderson, unpublished observations).

Lhx6 is expressed as cells from the MGE exit the cell cycle and migrate tangentially toward the striatum and cortex (Grigoriou et al., 1998; Lavdas et al., 1999; Gong et al., 2003; Liodis et al., 2007). More specifically, Lhx6 is detected in virtually all of the MGEderived, Nkx2.1-dependent subpopulations (mainly PV- or SOM-expressing) (Fogarty et al., 2007), whereas the bipolar CRexpressing subpopulation from the CGE are generally Lhx6 negative. Analysis of animals homozygous for an Lhx6 mutation showed that they maintain a normal number of GABA-positive $\left(\mathrm{GABA}^{+}\right)$interneurons in the neocortex and the hippocampus but lack the $\mathrm{PV}^{+}$and $\mathrm{SOM}^{+}$subpopulations (Liodis et al., 2007). In contrast, the $\mathrm{CR}^{+}$subpopulation of interneurons is reduced to a much lesser extent. It thus appears that Lhx6 activity is not required for the specification of the GABAergic neurotransmitter identity of cortical interneurons but is necessary for their specification into $\mathrm{Nkx} 2.1$ lineage ${ }^{+}$, MGE-derived subgroups.

In addition to its role in fate determination, Lhx6 is one of several transcription factors known to influence interneuron migration. Both the analysis of the Lhx6 mutant mice and a loss-offunction analysis by RNA interference suggest that Lhx6 required for the normal tangential migration of cortical interneurons (Alifragis et al., 2004; Liodis et al., 2007). In addition, after eventually reaching the cortex in the Lhx6 mutant mice, interneurons appear to have a profound defect in adopting the radial mode of migration within the cortical plate. Interestingly, despite the absence of Lhx6 from the majority of bipolar $\mathrm{CR}^{+}$interneurons, in Lhx6 mutants these neurons have lost their characteristic bipolar 
morphology and are distributed uniformly within the cortical plate as opposed to being preferentially positioned in the upper cortical layers in control animals. These findings argue that the Lhx6 mutation has both cell-autonomous and non-cellautonomous effects on subpopulations of cortical interneurons.

\section{Transcription regulation of interneuron migration and postnatal development}

Together with Lhx6, other homeodomain-containing transcription factors, including Dlx1 and Dlx2 (distal-less homeobox 1 and 2) as well as Arx1 (aristaless related homeobox 1), have been implicated in the regulation of interneuron migration. Dlx 1 and Dlx2 may promote interneuron migration by directly repressing the expression of neuropilin 2 (Le et al., 2007), a known regulator of interneuron migration (Marin et al., 2001). Dlx1 and Dlx2 are also required for Arx1 to be expressed at normal levels (Cobos et al., 2005a). Because Arx1 mutations in humans are associated with epilepsy and mental retardation (Kitamura et al., 2002) and Arx-deficient mice exhibit deficits in interneuron migration (Kitamura et al., 2002), defining the function of Arx will likely provide a better understanding of these and related disorders.

Because Arx is expressed in multiple progenitor and neuronal subpopulations in the forebrain, the function of this gene in distinct populations is being examined through an Arx-"floxed" transgenic line (J. Golden, unpublished observation). To study Arx function in the subcortically derived neurons of the telencephalon, this line has been crossed with Dlx5/6cre-internal ribosomal entry site-green fluorescent protein. Video EEG recordings demonstrate these mutant mice to have seizures, and the forebrains of these mice are being examined for evidence of interneuron pathology. In addition, the conditional mutant line has been crossed to other Cre lines: Pou3f4 (POU domain, class 3, transcription factor 4)-Cre, which recombines in most neural cells throughout the neuraxis, and Neurod6 (neurogenic differentiation 6)-Cre, which recombines in cortical pyramidal cells and mossy and granule cells of the dentate gyrus. Preliminary data indicate that Arx functions in the development of both interneurons and radially migrating projection neurons. Together, these experiments are providing important advances in characterizing Arx function that should advance the understanding of interneuron-related developmental brain disorders.

As mention above, in rodents interneurons do not complete their morphological and physiological differentiation until the third postnatal week. Postnatally, interneurons grow and pattern their axon and dendrite arborizations, establish subclass-specific patterns of synaptic connections with distinct target neurons as well as subcellular domains (soma, dendrites, and axons), and mature their electrophysiological properties. During this long period of interneuron differentiation, they dynamically regulate the expression of different transcriptional factors (Cobos et al., 2006). These changes in transcriptional regulation could be critical for the establishment and maintenance of dendrite and axon arborizations, synapse formation, and ultimately for fine-tuning inhibitory cortical circuits. Studies by Cobos et al. (2005b, 2007) on $D l x 1$ and $D l \times 2$ functions support this view. $D l x 1$ and $D l \times 2$ are coexpressed in interneuron progenitors and migrating cells, and then their expression levels lessen postnatally until they are maintained at low levels in adult cells (Saino-Saito et al., 2003; Cobos et al., 2005a). Analysis of $D l \times 1^{-/-} ; D l \times 2^{-/-}, D l \times 1^{-/-} ; D l \times 2^{+/-}$, and $D l \times 1^{-/-}$mutants reveals gene dose-sensitive functions of the $D l x$ transcription factors in the migration and neuronal differentiation of interneurons. $D l \times 1^{-1-} ; D l \times 2^{-1-}$ interneurons exhibit early and profound defects in their tangential migration and neu- rite growth (Anderson et al., 1997; Cobos et al., 2007). In Dlx1 $1^{-\prime}$ $-; D l \times 2^{+/-}$compound mutants, interneurons migrate tangentially to cortex but show deficits in their laminar positions and develop dendritic and axonal processes with increased length and decreased branching. Interneurons in $D l \times 1^{-1-}$ single mutants show no migration defects. However, abnormal dendritic morphology is seen in subsets of SOM- and CR-expressing interneurons in these mutants (Cobos et al., 2005). Notably, like conditional Dlx5/6cre:Arx-Flox mutants, Dlx $1^{-1-}$ mutant mice develop spontaneous seizures.

In summary, studies are beginning to reveal the transcriptional control of interneuron development from their fate determination in the subcortical telencephalon, tangential migration into the cerebral cortex, and terminal differentiation within the postnatal cortex. Because specific abnormalities in cortical interneuron development or function have been linked to common neuropsychiatric disorders such as epilepsy and schizophrenia (Levitt, 2005; Lewis et al., 2005), continuing efforts to connect the dots between key regulators of interneuron development are likely to uncover important disease-related genes and will also produce vital tools for the analysis of interneuron subtype function.

\section{References}

Alifragis P, Liapi A, Parnavelas JG (2004) Lhx6 regulates the migration of cortical interneurons from the ventral telencephalon but does not specify their GABA phenotype. J Neurosci 24:5643-5648.

Anderson SA, Eisenstat DD, Shi L, Rubenstein JL (1997) Interneuron migration from basal forebrain to neocortex: dependence on Dlx genes. Science 278:474-476.

Anderson SA, Kaznowski CE, Horn C, Rubenstein JL, McConnell SK (2002) Distinct origins of neocortical projection neurons and interneurons in vivo. Cereb Cortex 12:702-709.

Butt SJ, Fuccillo M, Nery S, Noctor S, Kriegstein A, Corbin JG, Fishell G (2005) The temporal and spatial origins of cortical interneurons predict their physiological subtype. Neuron 48:591-604.

Cavanagh ME, Parnavelas JG (1988) Development of somatostatin immunoreactive neurons in the rat occipital cortex: a combined immunocytochemical-autoradiographic study. J Comp Neurol 268:1-12.

Cavanagh ME, Parnavelas JG (1989) Development of vasoactive-intestinalpolypeptide-immunoreactive neurons in the rat occipital cortex: a combined immunohistochemical-autoradiographic study. J Comp Neurol 284:637-645.

Chiang C, Litingtung Y, Lee E, Young KE, Corden JL, Westphal H, Beachy PA (1996) Cyclopia and defective axial patterning in mice lacking Sonic hedgehog gene function. Nature 383:407-413.

Cobb SR, Buhl EH, Halasy K, Paulsen O, Somogyi P (1995) Synchronization of neuronal activity in hippocampus by individual GABAergic interneurons. Nature 378:75-78.

Cobos I, Broccoli V, Rubenstein JL (2005a) The vertebrate ortholog of Aristaless is regulated by Dlx genes in the developing forebrain. J Comp Neurol 483:292-303.

Cobos I, Calcagnotto ME, Vilaythong AJ, Thwin MT, Noebels JL, Baraban SC, Rubenstein JL (2005b) Mice lacking Dlx1 show subtype-specific loss of interneurons, reduced inhibition and epilepsy. Nat Neurosci 8:1059-1068

Cobos I, Long JE, Thwin MT, Rubenstein JL (2006) Cellular patterns of transcription factor expression in developing cortical interneurons. Cereb Cortex 16 [Suppl 1]:i82-i88.

Cobos I, Borello U, Rubenstein JL (2007) Dlx transcription factors promote migration through repression of axon and dendrite growth. Neuron 54:873-888.

Fogarty M, Grist M, Gelman D, Marín O, Pachnis V, Kessaris N (2007) Spatial genetic patterning of the embryonic neuroepithelium generates GABAergic interneuron diversity in the adult cortex. J Neurosci 27:10935-10946.

Fuccillo M, Rallu M, McMahon AP, Fishell G (2004) Temporal requirement for hedgehog signaling in ventral telencephalic patterning. Development 131:5031-5040. 
Gabbott PL, Bacon SJ (1996) Local circuit neurons in the medial prefrontal cortex (areas 24a,b,c, 25 and 32) in the monkey. II. Quantitative areal and laminar distributions. J Comp Neurol 364:609-636.

Gabbott PL, Jays PR, Bacon SJ (1997) Calretinin neurons in human medial prefrontal cortex (areas 24a,b,c, 32', and 25). J Comp Neurol 381:389-410.

Gong S, Zheng C, Doughty ML, Losos K, Didkovsky N, Schambra UB, Nowak NJ, Joyner A, Leblanc G, Hatten ME, Heintz N (2003) A gene expression atlas of the central nervous system based on bacterial artificial chromosomes. Nature 425:917-925.

Grigoriou M, Tucker AS, Sharpe PT, Pachnis V (1998) Expression and regulation of Lhx6 and Lhx7, a novel subfamily of LIM homeodomain encoding genes, suggests a role in mammalian head development. Development 125:2063-2074.

Kitamura K, Yanazawa M, Sugiyama N, Miura H, Iizuka-Kogo A, Kusaka M, Omichi K, Suzuki R, Kato-Fukui Y, Kamiirisa K, Matsuo M, Kamijo S, Kasahara M, Yoshioka H, Ogata T, Fukuda T, Kondo I, Kato M, Dobyns WB, Yokoyama M, Morohashi K (2002) Mutation of ARX causes abnormal development of forebrain and testes in mice and X-linked lissencephaly with abnormal genitalia in humans. Nat Genet 32:359-369.

Lavdas AA, Grigoriou M, Pachnis V, Parnavelas JG (1999) The medial ganglionic eminence gives rise to a population of early neurons in the developing cerebral cortex. J Neurosci 19:7881-7888.

Le TN, Du G, Fonseca M, Zhou QP, Wigle JT, Eisenstat DD (2007) Dlx homeobox genes promote cortical interneuron migration from the Basal forebrain by direct repression of the semaphorin receptor neuropilin-2. J Biol Chem 282:19071-19081.

Letinic K, Zoncu R, Rakic P (2002) Origin of GABAergic neurons in the human neocortex. Nature 417:645-649.

Levitt P (2005) Disruption of interneuron development. Epilepsia 46 [Suppl 7]:22-28.

Lewis DA, Hashimoto T, Volk DW (2005) Cortical inhibitory neurons and schizophrenia. Nat Rev Neurosci 6:312-324.

Liodis P, Denaxa M, Grigoriou M, Akufo-Addo C, Yanagawa Y, Pachnis V (2007) Lhx6 activity is required for the normal migration and specification of cortical interneuron subtypes. J Neurosci 27:3078-3089.

Marin O, Rubenstein JL (2003) Cell migration in the forebrain. Annu Rev Neurosci 26:441-483.

Marin O, Yaron A, Bagri A, Tessier-Lavigne M, Rubenstein JL (2001) Sorting of striatal and cortical interneurons regulated by semaphorinneuropilin interactions. Science 293:872-875.
Markram H, Toledo-Rodriguez M, Wang Y, Gupta A, Silberberg G, Wu C (2004) Interneurons of the neocortical inhibitory system. Nat Rev Neurosci 5:793-807.

Metin C, Baudoin JP, Rakic S, Parnavelas JG (2006) Cell and molecular mechanisms involved in the migration of cortical interneurons. Eur J Neurosci 23:894-900.

Miyoshi G, Butt SJ, Takebayashi H, Fishell G (2007) Physiologically distinct temporal cohorts of cortical interneurons arise from telencephalic Olig2expressing precursors. J Neurosci 27:7786-7798.

Poluch S, Jablonska B, Juliano SL (2007) Alteration of interneuron migration in a ferret model of cortical dysplasia. Cereb Cortex, in press.

Rymar VV, Sadikot AF (2007) Laminar fate of cortical GABAergic interneurons is dependent on both birthdate and phenotype. J Comp Neurol 501:369-380.

Saino-Saito S, Berlin R, Baker H (2003) Dlx-1 and Dlx-2 expression in the adult mouse brain: relationship to dopaminergic phenotypic regulation. J Comp Neurol 461:18-30.

Somogyi P, Tamas G, Lujan R, Buhl EH (1998) Salient features of synaptic organisation in the cerebral cortex. Brain Res Brain Res Rev 26:113-135.

Sussel L, Marin O, Kimura S, Rubenstein JL (1999) Loss of Nkx2.1 homeobox gene function results in a ventral to dorsal molecular respecification within the basal telencephalon: evidence for a transformation of the pallidum into the striatum. Development 126:3359-3370.

Tamamaki N, Yanagawa Y, Tomioka R, Miyazaki J, Obata K, Kaneko T (2003) Green fluorescent protein expression and colocalization with calretinin, parvalbumin, and somatostatin in the GAD67-GFP knock-in mouse. J Comp Neurol 467:60-79.

Tamas G, Buhl EH, Lorincz A, Somogyi P (2000) Proximally targeted GABAergic synapses and gap junctions synchronize cortical interneurons. Nat Neurosci 3:366-371.

Thomson AM, West DC, Hahn J, Deuchars J (1996) Single axon IPSPs elicited in pyramidal cells by three classes of interneurones in slices of rat neocortex. J Physiol (Lond) 496:81-102.

Wonders CP, Anderson SA (2006) The origin and specification of cortical interneurons. Nat Rev Neurosci 7:687-696.

Xu Q, Cobos I, De La Cruz E, Rubenstein JL, Anderson SA (2004) Origins of cortical interneuron subtypes. J Neurosci 24:2612-2622.

Xu Q, Wonders CP, Anderson SA (2005) Sonic hedgehog maintains the identity of cortical interneuron progenitors in the ventral telencephalon. Development 132:4987-4998. 